\title{
Laboratory Evaluation of SBS Modified Asphalt Binder Containing GTR, SIS, and PE
}

\author{
Hyun Hwan Kim, ${ }^{1}$ Mithil Mazumder, ${ }^{1}$ Moon-Sup Lee ${ }^{(D)},{ }^{2}$ and Soon-Jae Lee ${ }^{1}$ \\ ${ }^{1}$ Texas State University, San Marcos, TX 78666, USA \\ ${ }^{2}$ Korea Institute of Civil Engineering and Building Technology, Goyang-Si 10223, Gyeonggi, Republic of Korea \\ Correspondence should be addressed to Moon-Sup Lee; truepath@kict.re.kr
}

Received 15 July 2020; Revised 25 October 2020; Accepted 4 November 2020; Published 19 November 2020

Academic Editor: Yuqing Zhang

Copyright (c) 2020 Hyun Hwan Kim et al. This is an open access article distributed under the Creative Commons Attribution License, which permits unrestricted use, distribution, and reproduction in any medium, provided the original work is properly cited.

\begin{abstract}
Performance properties of polymer modified asphalt (PMA) binders with Styrene-isoprene-styrene (SIS), petroleum resin (PE), and ground tire rubber (GTR) were evaluated at high, intermediate, and low temperatures. Styrene-butadiene-styrene (SBS) PMA binder of PG 76-22 was used as a base binder. The PG76 SBS PMA binders were blended with SIS, PE, and three different GTR contents $(0,5$, and $10 \%)$. The binders were artificially short-term and long-term aged using rolling thin film oven (RTFO) and pressure aging vessel (PAV) procedures. Superpave binder tests were conducted on the binders through rotational viscometer (RV), dynamic shear rheometer (DSR), and bending beam rheometer (BBR). Multiple stress creep recovery (MSCR) test was also performed to evaluate the rutting property. The results of this study indicated that (1) the addition of PE can decrease the binder viscosity, (2) although the incorporation of GTR and SIS significantly improve the rutting resistance of the binders, the effect of PE is found to be insignificant, (3) PE is observed to have positive effect on the cracking properties of control PG76 SBS PMA binder blended with SIS and GTR, and (4) incorporation of PE might be an useful option to improve the workability of high performance PMA binder in lieu with maintaining good rutting and cracking resistance.
\end{abstract}

\section{Introduction}

These days, flexible pavement is exposed to severe conditions, including heavier traffic loads and harsh climate. The addition of polymer materials has been emerged and applied to extend the pavement's service life. Not only the performance but also economic benefit can be obtained by the use of polymer materials in the asphalt industry. Even though polymer modified asphalt (PMA) binder increased initial construction cost compared to the unmodified conventional mixes, overall life cycle cost savings over 40 years is substantial [1].

SBS is the most common polymer which is used to produce high quality PMA binder [2]. SBS modified binder is known to be durable pavement material which has improved bonding strength with aggregate based on a three-dimensional network [3]. The formation of network improves not only rutting resistance but also cracking resistance at low temperature by microdamage accumulation [4]. Therefore, the SBS modified asphalt binder is mostly used for the construction of highway that are exposed to high traffic volume and heavy loads. Due to the rapid increase of heavy traffic volume and demand of longer service life of pavement, it is required to incorporate new and sustainable materials to develop the properties of binder which has better resistance to the rutting and cracking.

Ground tire rubber (GTR) is one of the popular additives in asphalt industry. The huge amount of scrap tires (approximately 40 million of tires) are disposed on landfills in the United States [5]. The use of GTR in asphalt pavement is already accepted as a great solution which consumes these wasted tires resulting in environmental benefits and solving the landfill issue. Also, the addition of GTR improves the rutting property due to increased stiffness and elasticity at a high temperature [6]. It extends the fatigue life of mixture 
through enhanced asphalt film which coated the aggregate in mixture [7]. GTR modification takes significant role in improving the asphalt binder through reduced stiffness at a low temperature, decreased traffic noise, and reduced maintenance costs [8-18]. In previous research [19], the incorporation of GTR and SBS has been evaluated and it showed enhanced performances for rheological properties at high and low temperature.

In addition, the use of SIS is emerged in asphalt industry as a relatively new polymer additive. According to the previous research $[20,21]$, the molecule chain of isoprene in SIS increases the complex modulus at high temperature and due to its branch methyl in the isoprene group it has better tenacity and compatibility with other materials. Although it needs specific temperature control and mixing time, the dispersion of SIS in asphalt binder is homogeneous like SBS PMA binder. Completely dispersed polymers caused a change in the molecular structure of the asphalt binder [22].

Even though the addition of several polymers improves binder performances, it also increases the viscosity. High viscosity generates other concerns such as more fuel consumption and carbon generation. According to the previous research [23], the application of petroleum resin $(\mathrm{PE})$ is effective to improve the performance of SBS modified binder. Also, it is expected that the addition of PE may decrease the binder viscosity. As a result, if the incorporation of PE can develop PMA binder without increasing the viscosity, it might be considered to apply for high performance asphalt pavement.

The purpose of this study is to evaluate the performances properties of SBS PMA binders containing SIS, GTR, and PE modifiers. The binders were aged through the RTFO and PAV procedures. Superpave binder tests were conducted to characterize at three aging states (original, short-term aging, and long-term aging). Furthermore, the multiple stress creep recovery (MSCR) test was applied to more effectively evaluate the rutting property of asphalt binders. Figure 1 shows a flow chart of the experimental design.

\section{Experimental Design}

2.1. Materials. Commercial SBS modified binder of PG 76-22 was used as a base binder for this study. Table 1 exhibits the base binder properties. SIS contains the isoprene (2-methyl1,3-butadiene; $\mathrm{C}_{5} \mathrm{H}_{8}$ ) which is produced by many plants and animals. Its polymers are the main component of natural rubber. Therefore, the addition of SIS is expected to result in higher aging resistance and good blend stability and improve elastic response, superior cohesion, tensile strength, and lowtemperature flexibility. The SIS of $5 \%$ by the weight of binder was added and mixed with PG 76-22 binder. The mixing conditions were followed: $177^{\circ} \mathrm{C}$ for 60 minutes by an open blade mixer at $700 \mathrm{rpm}$.

Figure 2 shows the $\mathrm{C} 9$ petroleum resin (PE). 3\% of $\mathrm{C} 9$ $\mathrm{PE}$ is added into SBS PMA binder containing SIS. C9 have the potential to further improve the properties of PMA binders without viscosity increase. It is expected that the performance and grade of SBS PMA binders with SIS are able to be tuned and modified cheaply. C9 PE is from C9 aromatic fractions produced in steam crackers of petrochemicals to produce ethylene and propylene. The mixing conditions were as follows: $177^{\circ} \mathrm{C}$ for 1 minute by an open blade mixer at $700 \mathrm{rpm}$.

High performance PMA binders were mixed with surface treated GTR. Table 2 shows the gradation of GTR. The percentages of GTR were $5 \%$ and $10 \%$ by weight of the base PMA binder. The swelling and degradation of rubber particles are highly dependent by mixing temperature and time $[24,25]$. The wet process was applied to produce rubberized PMA binder in the laboratory at $177^{\circ} \mathrm{C}$ for 30 minutes at a blending speed of $700 \mathrm{rpm}$ considering the modification mechanism of polymer additives. The consistency of the PMA binder samples was maintained using only one batch of GTR during the study.

2.2. Superpave Binder Tests. Superpave asphalt binder tests are used to measure asphalt's performance at three stages of its life: in its original state, after mixing and construction, and after in-service aging. In this study, the selected binder test procedures included the viscosity test (AASHTO T 316), the dynamic shear rheometer (DSR) test (AASHTO T 315), and the bending beam rheometer (BBR) test (AASHTOT 313). Three replicate samples were tested, and the results were reported as the average of these tests. A $10.5 \mathrm{~g}$ sample of binders was tested with a number 27 spindle in the Brookfield rotational viscometer at $180^{\circ} \mathrm{C}$. In the DSR test, the binders (Original, RTFO residual, and $\mathrm{RTFO}+\mathrm{PAV}$ residual) were tested at a frequency of 10 radians per second which is equal to approximately $1.59 \mathrm{~Hz}$. Each asphalt binder in both the original state (unaged) and short-time aged state is used to determine the $\mathrm{G}^{*} / \sin \delta$. The $\mathrm{G}^{*} \sin \delta$ at intermediate temperature was measured to evaluate the fatigue cracking property for RTFO + PAV residual binders. The BBR test was conducted on asphalt beams $(125 \times 6.35 \times 12.7 \mathrm{~mm})$ at $-12^{\circ} \mathrm{C}$, and the creep stiffness $(\mathrm{S})$ of the binder was measured at a loading time of $60 \mathrm{~s}$. A constant load of $100 \mathrm{~g}$ was then applied to the beam of the binder, which was supported at both ends, and the deflection of center point was measured continuously. Testing was performed on long-term aged state (RTFO + PAV residual samples).

2.3. Multiple Stress Creep Recovery (MSCR) Tests. DSR equipment is used to conduct MSCR test for the rubberized PMA binders. The test is conducted according to AASHTO TP 70 specification at $76^{\circ} \mathrm{C}$. All binders were tested in short-term aged state. The samples are tested in creep and recovery at two stress levels: $0.1 \mathrm{kPa}$ and $3.2 \mathrm{kPa}$. Two parameters are derived from analyzing the MSCR test, that is, the nonrecoverable creep compliance $\left(\mathrm{J}_{\mathrm{nr}}\right)$ and percent recovery (\%rec). As shown in Figure 3, the binder is subjected to creep loading and unloading cycle of $1 \mathrm{sec}$ and 9 secs, respectively, at stress levels of $0.1 \mathrm{kPa}$ and $3.2 \mathrm{kPa}$ and ten cycles of loading are applied at each stress level. The output of MSCR test is used to calculate 


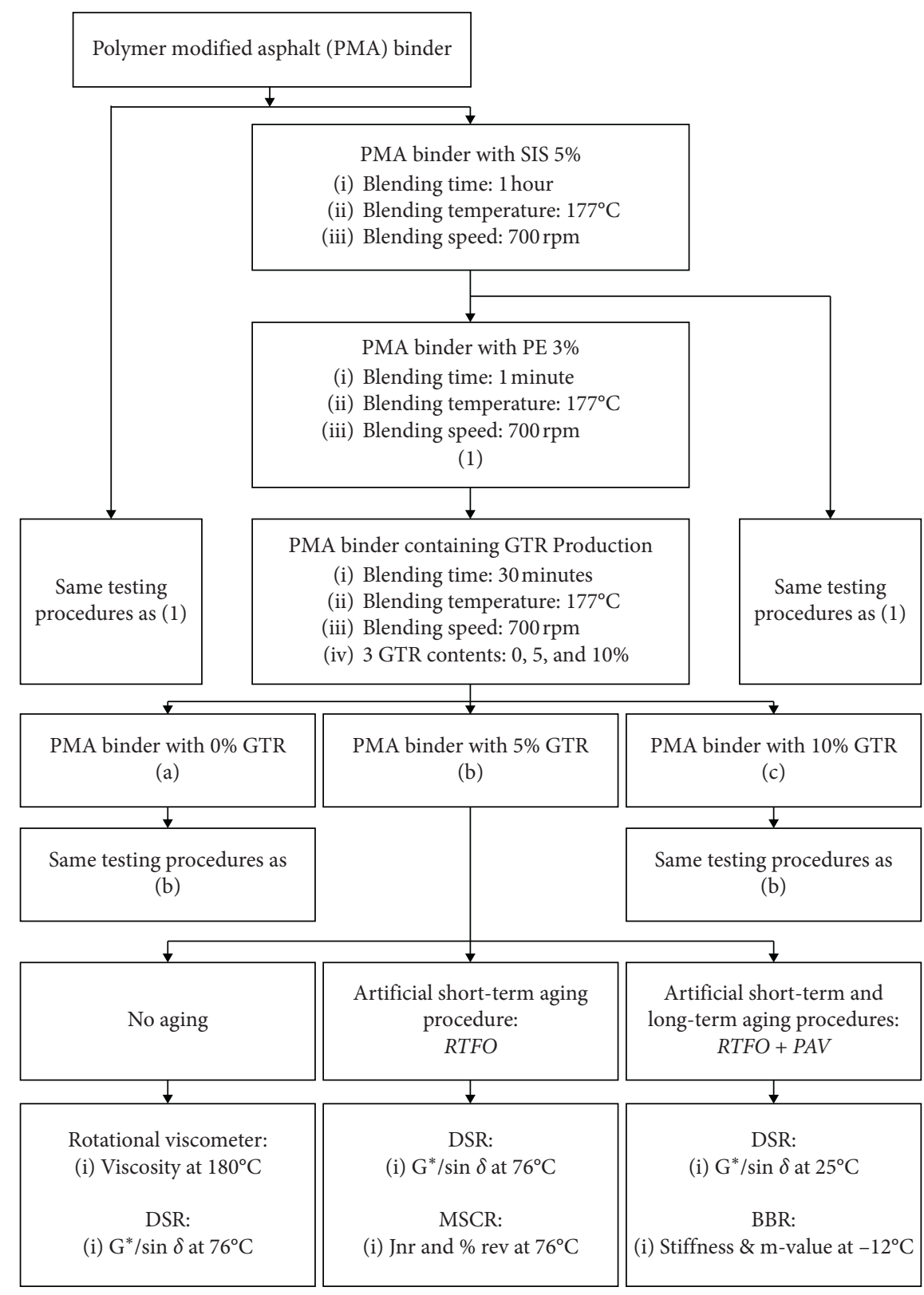

FIgURE 1: Flow chart of experimental design procedures.

Table 1: Properties of base asphalt binder (PG 76-22).

\begin{tabular}{lcc}
\hline Aging states & Test properties & Test result \\
\hline Unaged binder & Viscosity @ $135^{\circ} \mathrm{C}(\mathrm{Pa}-\mathrm{s})$ & 3.244 \\
& $\mathrm{G}^{*} / \sin \delta @ 76^{\circ} \mathrm{C}(\mathrm{kPa})$ & 1.9 \\
$\mathrm{RTFO}$ aged residual & $\mathrm{G}^{*} / \sin \delta @ 76 \mathrm{C}(\mathrm{kPa})$ & 3.3 \\
& $\mathrm{G}^{*} \sin \delta @ 25^{\circ} \mathrm{C}(\mathrm{kPa})$ & 3650 \\
RTFO + PAV aged residual & Stiffness @ $-12^{\circ} \mathrm{C}(\mathrm{MPa})$ & 285 \\
& $m$ value @ $-12^{\circ} \mathrm{C}$ & 0.302 \\
\hline
\end{tabular}

nonrecoverable creep compliance $\left(J_{n r}\right)$ and percent recovery (\%rec) for quantifying the rutting susceptibility of asphalt binders. The nonrecoverable creep compliance $\left(\mathrm{J}_{\mathrm{nr}}\right)$, which is determined by dividing nonrecoverable shear strain by the shear stress, is used to evaluate the rutting potential of the asphalt binder.
2.4. Statistical Analysis Method. A statistical analysis was performed using the Statistical Analysis System (SAS) program to conduct an analysis of variance (ANOVA) and Fisher's Least Significant Difference (LSD) comparison with $\alpha=0.05$. The ANOVA was performed first to determine whether significant differences among sample 


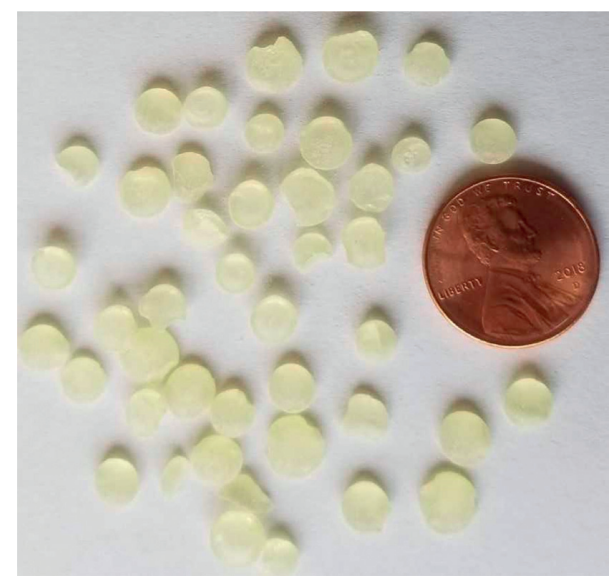

FIgURe 2: Petroleum resin (PE).

TABLE 2: Gradation of GTR used in this study.

\begin{tabular}{lcc}
\hline Sieve no. $(\mu \mathrm{m})$ & \multicolumn{2}{c}{ GTR } \\
& \% retained & \% cumulative retained \\
\hline $30(600)$ & 0 & 0.0 \\
$40(425)$ & 3.6 & 3.6 \\
$50(300)$ & 68.5 & 72.1 \\
$80(180)$ & 11.1 & 83.2 \\
$100(150)$ & 10.0 & 93.2 \\
$200(75)$ & 6.1 & 99.3 \\
\hline
\end{tabular}

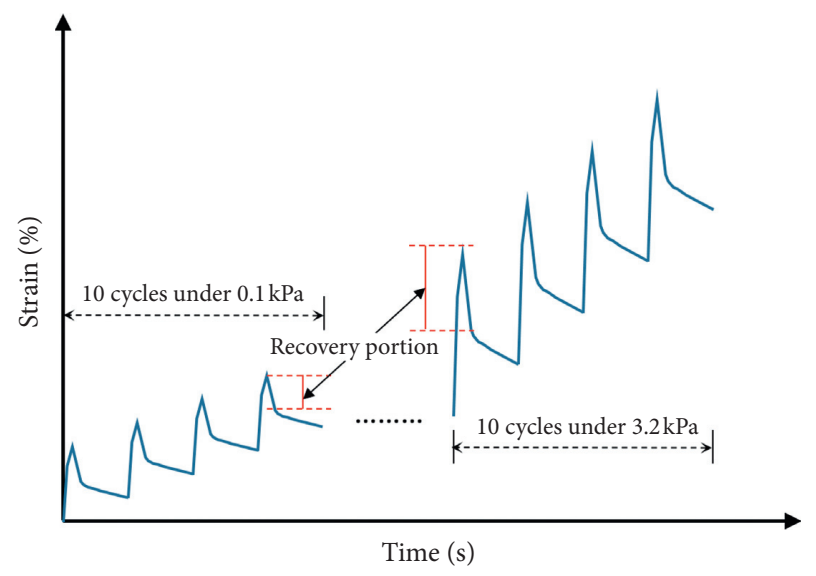

Figure 3: 10 cycles of creep and recovery at two stress levels of $0.1 \mathrm{kPa}$ and $3.2 \mathrm{kPa}$.

means existed. In the analyses of this study, the significance level was 95, indicating that each finding had a $95 \%$ chance of being true. Upon determining that there were differences among sample means using the ANOVA, the LSD was then calculated. The LSD is defined as the observed differences between two sample means necessary to declare the corresponding population means difference. Once the LSD was calculated, all pairs of sample means were compared. If the difference between two sample means was greater than or equal to the LSD, the population means were declared to be statistically different [26].

\section{Results and Discussion}

3.1. Rotational Viscosity. The mixing temperature of the asphalt mixture is generally selected based on the binder viscosity which indicates the ability to pump and coat the aggregate from the asphalt plant. Figure 4 shows the experimental values of the viscosities measured at $180^{\circ} \mathrm{C}$. The viscosity values were not measured at standard testing temperature $\left(135^{\circ} \mathrm{C}\right)$, due to the high viscosity characteristics associated with the addition of SIS. Thus, viscosity results measured at $180^{\circ} \mathrm{C}$ exhibited to have better comparisons and trends. Application of GTR is obviously effective to increase the viscosity. In addition, all binder viscosity values are almost proportionally increased with the increase of GTR contents in all PMA binders. PG 7622 binder with SIS showed higher viscosity compared to control PMA binder without SIS. However, the viscosity of these binders is observed to have decreased by approximately $10 \%$ with addition of $\mathrm{PE}$. This indicates that $\mathrm{PE}$ is effective to reduce the binder viscosity as expected.

The statistical significance of the viscosity as a function of GTR percentages and the incorporation of SIS and PE are examined and the results are shown in Table 3. This data illustrates that GTR contents has a significant effect on viscosity values regardless of types of modified binder. The addition of SIS has significantly influenced the viscosity in all GTR contents. Also, the results are found to be statistically significant on the effect of PE which reduced the binder viscosity.

3.2. Rutting Property. The higher $\mathrm{G}^{*} / \sin \delta$ from the DSR test shows the binders are stronger against rutting or permanent deformation at high pavement temperatures. In original state and short-term aged state, the binders were tested to measure the $\mathrm{G}^{*} / \sin \delta$ values at $76^{\circ} \mathrm{C}$. The results are shown in Figure 5. The addition of GTR resulted in higher $\mathrm{G}^{*} / \sin \delta$ values compared to control PG76 binder with/without SIS in original state. Also, the PG76 with SIS showed higher $\mathrm{G}^{*} / \sin \delta$ values compared to the PG76 without SIS. The similar trends were observed in short-term aged state. It indicates that both additives, GTR and SIS, are effective to improve the rutting property. On the other hand, PG76 + SIS5\% + PE3\% binders showed insignificant differences on $\mathrm{G}^{*} / \sin \delta$ values compared to the corresponding same GTR percentage contents of PG76 + SIS5\% without PE regardless of aging state. It indicates that the application of PE to PG76+SIS5\% binder can maintain high rutting resistance with better workability due to the less binder viscosity. On average, the $\mathrm{G}^{*} / \sin \delta$ values of PG76+SIS5\%+PE3\%+GTR are decreased by less than $0.5 \mathrm{kPa}$ at both aging states compared to the corresponding binders without PE.

The statistical significance of the change in the $\mathrm{G}^{*} / \sin$ $\delta$ value as a function of the addition of SIS, PE, and GTR contents was examined and results are shown in Table 4. 


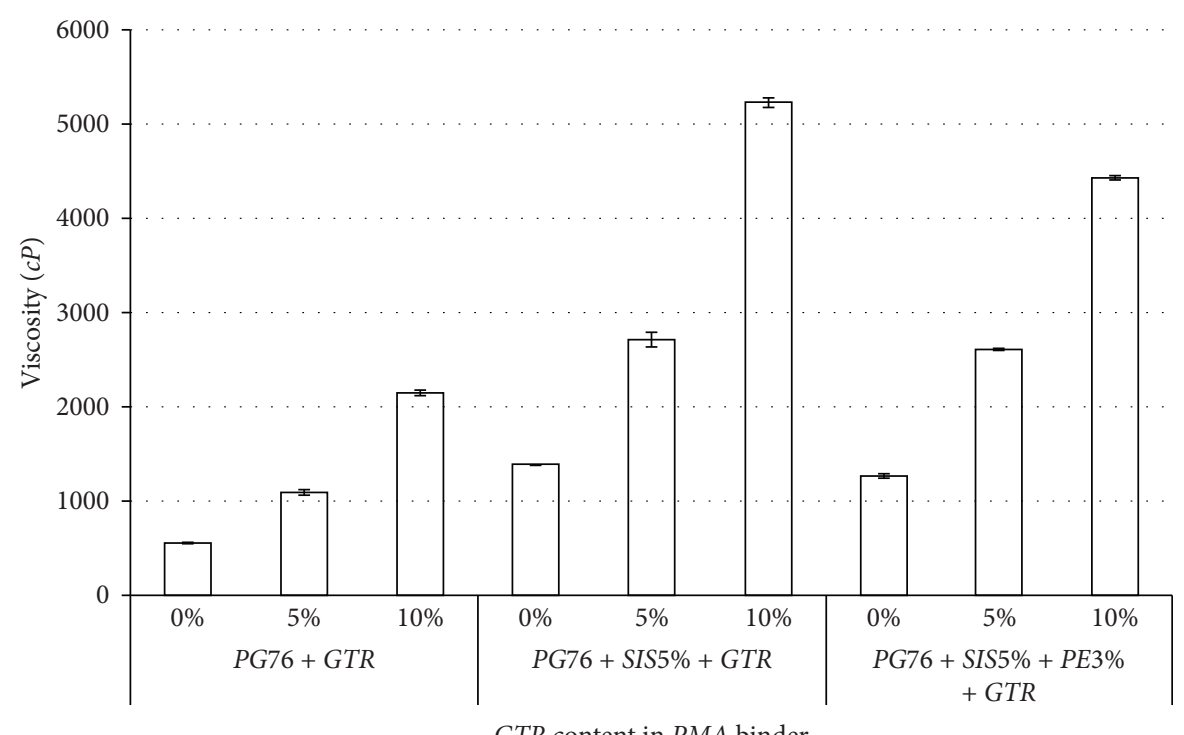

GTR content in PMA binder

Figure 4: Viscosity of the PMA binder with SIS, PE, and GTR at $180^{\circ} \mathrm{C}$.

TABLE 3: Statistical analysis results of the viscosity at $180^{\circ} \mathrm{C}$ as a function of SIS, PE, and GTR content $(\alpha=0.05)$.

\begin{tabular}{|c|c|c|c|c|c|c|c|c|c|c|}
\hline \multirow[t]{2}{*}{ Viscosity } & & \multicolumn{3}{|c|}{ PG76 + GTR } & \multicolumn{3}{|c|}{ PG76 + SIS5\% + GTR } & \multicolumn{3}{|c|}{$\begin{array}{c}\text { PG76 + SIS5 } \%+\text { PE } 3 \%+ \\
\text { GTR }\end{array}$} \\
\hline & & $0 \%$ & $5 \%$ & $10 \%$ & $0 \%$ & $5 \%$ & $10 \%$ & $0 \%$ & $5 \%$ & $10 \%$ \\
\hline \multirow{3}{*}{ PG76 + GTR } & $0 \%$ & - & $S$ & $S$ & $\mathrm{~S}$ & $S$ & $S$ & $S$ & S & $S$ \\
\hline & $5 \%$ & & - & $S$ & $\mathrm{~S}$ & $S$ & $S$ & $S$ & $S$ & $S$ \\
\hline & $10 \%$ & & & - & $\mathrm{S}$ & $\mathrm{S}$ & $S$ & $\mathrm{~S}$ & $S$ & S \\
\hline \multirow{3}{*}{ PG76 + GTR + SIS5\% } & $0 \%$ & & & & - & $S$ & S & $\mathrm{S}$ & S & S \\
\hline & $5 \%$ & & & & & - & $S$ & $\mathrm{~S}$ & $S$ & S \\
\hline & $10 \%$ & & & & & & - & $\mathrm{S}$ & $S$ & $\mathrm{~S}$ \\
\hline \multirow{3}{*}{ PG76 + GTR + SIS5\% + PE3\% } & $0 \%$ & & & & & & & - & $S$ & $S$ \\
\hline & $5 \%$ & & & & & & & & - & S \\
\hline & $10 \%$ & & & & & & & & & - \\
\hline
\end{tabular}

$\mathrm{N}$ : nonsignificant; S: significant.

The significant difference is observed with the addition of SIS at both aging states. In addition, the GTR contents have a significant effect on the $\mathrm{G}^{*} / \sin \delta$ value within each aging state. However, it is found that the statistical difference with the incorporation of PE is insignificant at both aging states compared to the corresponding same GTR percentage contents without PE.

3.3. Multiple Stress Creep Recovery (MSCR) Test. Short-term aged binder samples were used to conduct the MSCR test according to AASHTO TP 70. MSCR test and specification represent a technical improvement over the current performance grade (PG) specification for better characterization of the high temperature property of an asphalt binder [27]. Nonrecoverable creep compliance $\mathrm{J}_{\mathrm{nr}}$ represents the rutting of the PMA binder at high temperature. \% recovery characterizes the delayed elastic response of the asphalt binder. The high delayed elastic response is an indication that the asphalt binder has a significant elastic component at the test temperature. Figure 6 shows the variation of creep compliance at $3.2 \mathrm{kPa}$ stress level and percent recovery of the PMA binders with GTR at $76^{\circ} \mathrm{C}$. The addition of GTR significantly decreased the $\mathrm{J}_{\mathrm{nr}}$ values in PMA binders as shown in Figure 6(a). In general, all binders observed to have reduced the nonrecoverable creep compliance $\left(\mathrm{J}_{\mathrm{nr}}\right)$ of the base PMA binders with the addition of GTR. Addition of SIS reduces $\mathrm{J}_{\mathrm{nr}}$ to very low value of approximately 0.5 . \%rec is also found to have increasing trend with increase of GTR contents for all PMA binder types. As GTR addition increased by $5 \%$, \%rec increased by approximately $24 \%$ for control PG76 binders. The addition of SIS was also significantly increased the \%rec with comparison to the base PMA binders without GTR. It is considered that the addition of SIS and GTR have positive effect on rutting resistance associated with elastic component. On the other hand, it was found that the difference between PG76 + SIS5\% + PE3\% + $10 \%$ and PG76 + SIS5\% + GTR10\% without PE binder insignificant. The effect of PE to reduce \%rec is observed to be compensated by high GTR content. 


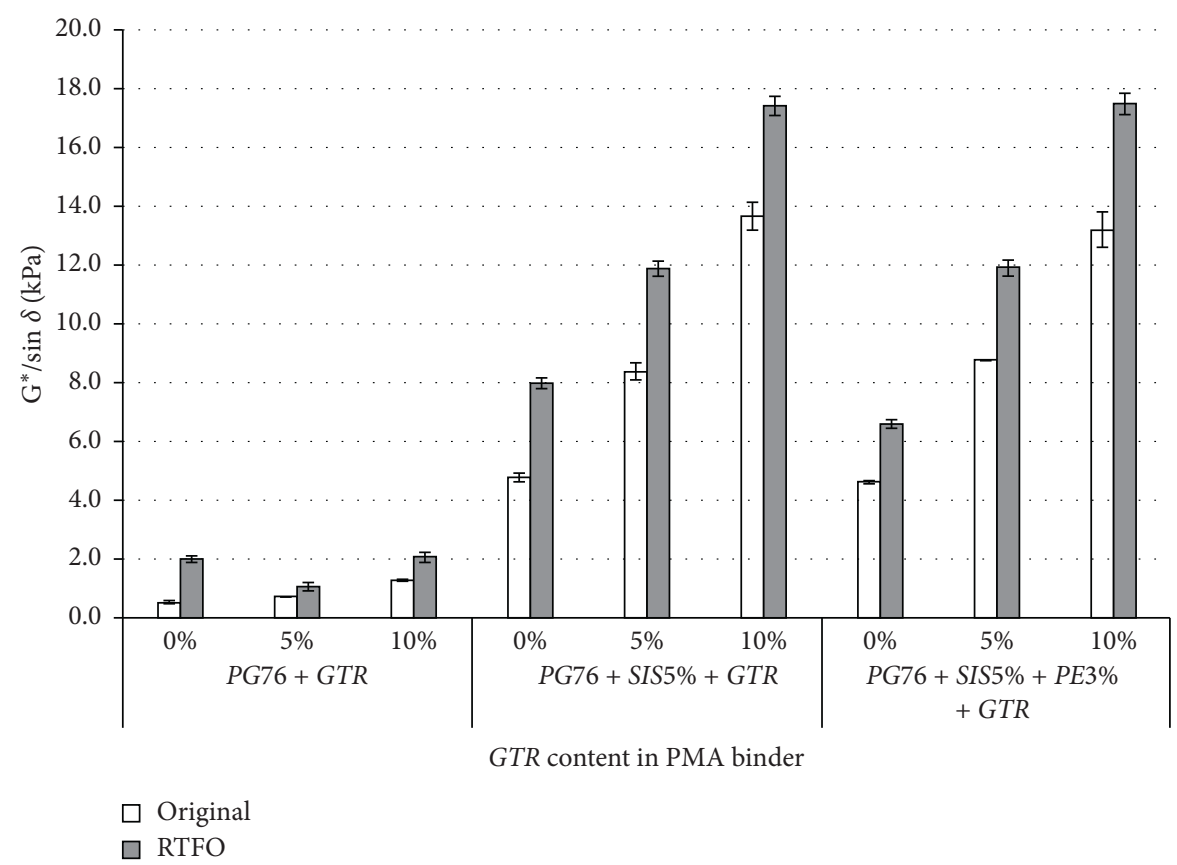

Figure 5: G* $/ \sin \delta$ of the PMA binders with SIS, PE, and GTR at $76^{\circ} \mathrm{C}$.

TABLe 4: Statistical analysis results of the $\mathrm{G}^{*} / \sin \delta$ as a function of addition of SIS, PE, and GTR content $(\alpha=0.05)$.

\begin{tabular}{|c|c|c|c|c|c|c|c|c|c|c|}
\hline \multirow[t]{2}{*}{$\mathrm{G}^{*} / \sin \delta$ at $76^{\circ} \mathrm{C}$} & & \multicolumn{3}{|c|}{ PG76 + GTR } & \multicolumn{3}{|c|}{ PG76 + GTR + SIS5\% } & \multicolumn{3}{|c|}{$\begin{array}{c}\text { PG76 + GTR + SIS5 } \%+ \\
\text { PE3 } \%\end{array}$} \\
\hline & & $0 \%$ & $5 \%$ & $10 \%$ & $0 \%$ & $5 \%$ & $10 \%$ & $0 \%$ & $5 \%$ & $10 \%$ \\
\hline \multicolumn{11}{|l|}{ (Original) } \\
\hline \multirow{3}{*}{ PG76 + GTR } & $0 \%$ & - & $\mathrm{N}$ & S & $\mathrm{S}$ & $\mathrm{S}$ & S & S & S & S \\
\hline & $5 \%$ & & - & S & $\mathrm{S}$ & $S$ & S & S & S & S \\
\hline & $10 \%$ & & & - & $\mathrm{S}$ & S & S & S & S & S \\
\hline \multirow{3}{*}{ PG76 + GTR + SIS5\% } & $0 \%$ & & & & - & $\mathrm{S}$ & S & $\mathrm{N}$ & S & S \\
\hline & $5 \%$ & & & & & - & S & S & $\mathrm{N}$ & S \\
\hline & $10 \%$ & & & & & & - & S & S & $\mathrm{N}$ \\
\hline \multirow{3}{*}{ PG76 + GTR + SIS5 $\%+$ PE3 $\%$} & $0 \%$ & & & & & & & - & $S$ & $S$ \\
\hline & $5 \%$ & & & & & & & & - & $S$ \\
\hline & $10 \%$ & & & & & & & & & - \\
\hline \multicolumn{11}{|l|}{ (RTFO) } \\
\hline \multirow{3}{*}{ PG76 + GTR } & $0 \%$ & - & $\mathrm{S}$ & $\mathrm{N}$ & $\mathrm{S}$ & $\mathrm{S}$ & S & $\mathrm{S}$ & S & S \\
\hline & $5 \%$ & & - & S & $\mathrm{S}$ & $S$ & S & S & S & $\mathrm{S}$ \\
\hline & $10 \%$ & & & - & $\mathrm{S}$ & $\mathrm{S}$ & S & S & S & $\mathrm{S}$ \\
\hline \multirow{3}{*}{ PG76 + GTR + SIS5\% } & $0 \%$ & & & & - & $\mathrm{S}$ & S & $\mathrm{S}$ & S & S \\
\hline & $5 \%$ & & & & & - & S & S & $\mathrm{N}$ & S \\
\hline & $10 \%$ & & & & & & - & S & S & $\mathrm{N}$ \\
\hline \multirow{3}{*}{ PG76 + GTR + SIS5 $\%+$ PE3 $\%$} & $0 \%$ & & & & & & & - & $\mathrm{S}$ & $\mathrm{S}$ \\
\hline & $5 \%$ & & & & & & & & - & S \\
\hline & $10 \%$ & & & & & & & & & - \\
\hline
\end{tabular}

N: nonsignificant; S: significant.

Table 5 presents the statistical analysis results of the MSCR as a function of addition of SIS, PE, and GTR content. In statistical analysis of $\mathrm{J}_{\mathrm{nr}}$, it is shown that there was no significant difference by SIS and PE and GTR content except for PG76 + GTR5\% and 10\%, meaning that the effect of additives including SIS, PE, and GTR is insignificant on $\mathrm{J}_{\mathrm{nr}}$ result. The results of \%rec showed that there was a significant difference due to the two additives and GTR content.
However, there was insignificant difference between PG76 + SIS5\% + GTR10\% and PG76 + SIS5\% + PE3\% with the same $10 \%$ GTR as shown in Figure 6(b).

3.4. Fatigue Cracking Property. The values of $\mathrm{G}^{*} \sin \delta$ from the DSR are used to identify a fatigue cracking characteristic, where $\mathrm{G}^{*}$ represents stiffness and $\delta$ is a viscous or elastic 


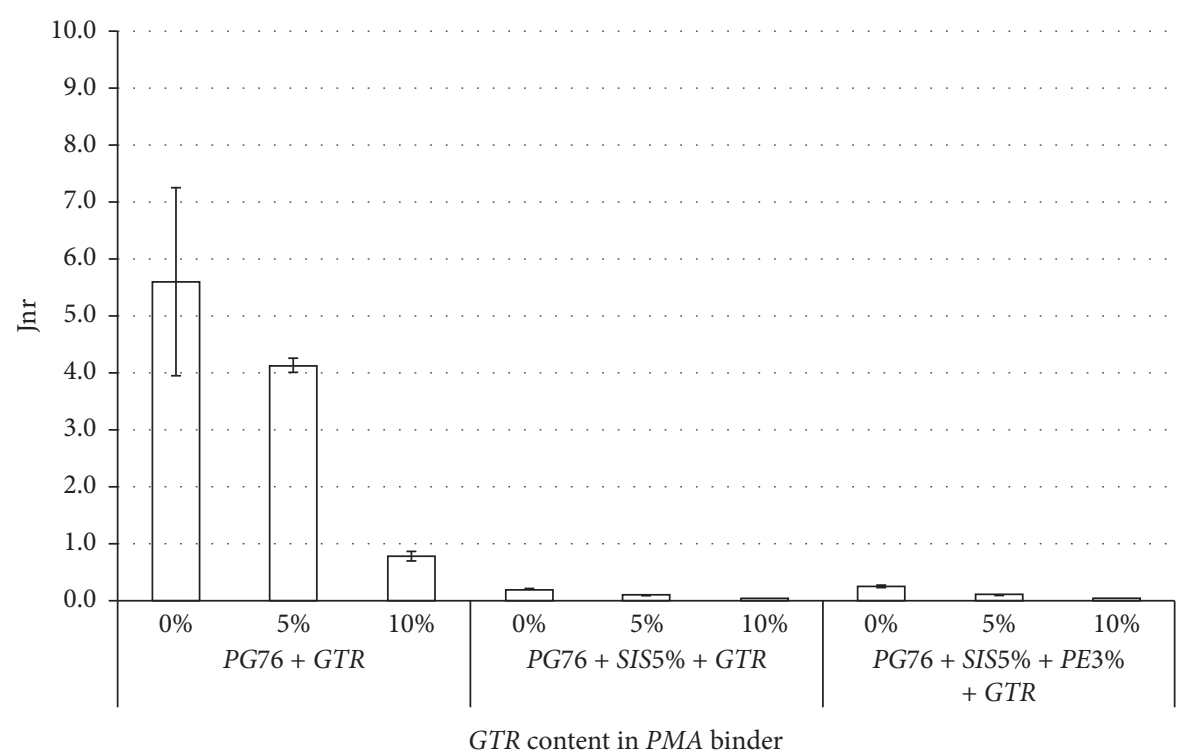

(a)

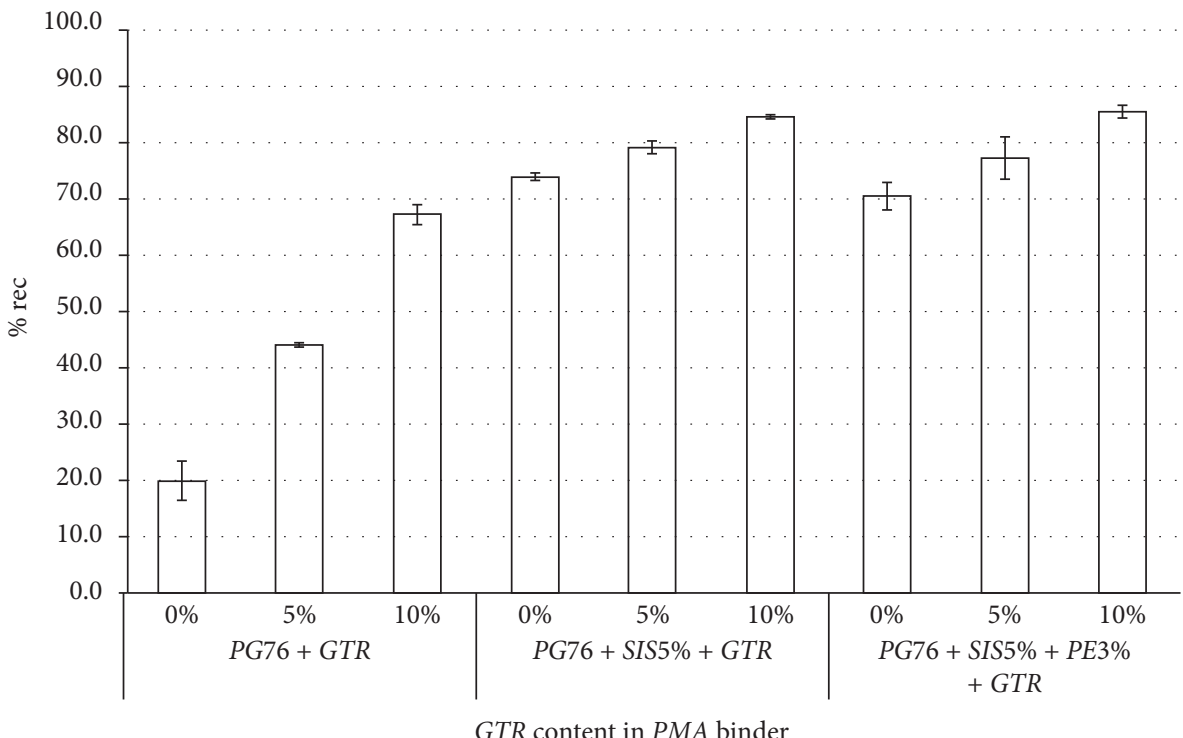

(b)

FIgURE 6: Variations in creep compliance and percent recovery of the PMA binder with SIS, PE, and GTR at $76^{\circ} \mathrm{C}$; (a) $\mathrm{J}_{\mathrm{nr}}$ and (b) \%rec.

indicator. Low values are desirable attribute due to resistance to fatigue cracking. The $\mathrm{G}^{*} \sin \delta$ values of the binders ( RTFO + PAV residual) were measured using the DSR at $25^{\circ} \mathrm{C}$ and the results are illustrated in Figure 7. The GTR 0\% binders exhibited the highest $\mathrm{G}^{*} \sin \delta$ value in each base binder type. However, addition of GTR significantly decreased the $\mathrm{G}^{*} \sin \delta$ values. GTR $10 \%$ resulted in the lowest $\mathrm{G}^{*} \sin \delta$ value as expected. These results indicate that the GTR has positive effect on the resistance of fatigue cracking. The binders modified with SIS and PE also showed improved cracking resistance. As a result, PG76 + SIS5\% + PE3\% + GTR $10 \%$ exhibited the lowest $\mathrm{G}^{*} \sin \delta$ value, suggesting that the subsequent addition of SIS and PE gradually improves the cracking performance of binders at intermediate temperature.
The statistical results of $\mathrm{G}^{*} \sin \delta$ values are shown in Table 6. In general, the results showed that, within each base binder type, the GTR contents have a significant difference in the $\mathrm{G}^{*} \sin \delta$ value. Also, the data indicates that the presence of SIS has a significant effect on fatigue cracking property.

3.5. Thermal Cracking Property. Creep stiffness and $m$ value from BBR test are the parameters considered for thermal cracking at low temperature. Creep stiffness is the resistance of the asphalt binder to creep loading, and the $m$ value is the change in the creep stiffness with time during loading. A maximum creep stiffness of $300 \mathrm{MPa}$ and a 
TABLE 5: Statistical analysis results of the MSCR as a function of addition of SIS, PE and GTR content $(\alpha=0.05)$.

\begin{tabular}{|c|c|c|c|c|c|c|c|c|c|c|}
\hline & & \multicolumn{3}{|c|}{ PG76 + GTR } & \multicolumn{3}{|c|}{ PG76 + SIS5\% + GTR } & \multicolumn{3}{|c|}{$\begin{array}{c}\text { PG76 + SIS5 } \%+\text { PE3 } \%+ \\
+ \text { GTR }\end{array}$} \\
\hline & & $0 \%$ & $5 \%$ & $10 \%$ & $0 \%$ & $5 \%$ & $10 \%$ & $0 \%$ & $5 \%$ & $10 \%$ \\
\hline \multicolumn{11}{|l|}{$\mathrm{Jnr}_{\mathrm{nr}}$} \\
\hline & $0 \%$ & - & $\mathrm{S}$ & S & $S$ & S & $\mathrm{S}$ & $\mathrm{S}$ & $\mathrm{S}$ & $\mathrm{S}$ \\
\hline \multirow{2}{*}{ PG76 + GTR } & $5 \%$ & & - & S & $S$ & $S$ & $S$ & $\mathrm{~S}$ & $\mathrm{~S}$ & S \\
\hline & $10 \%$ & & & - & $\mathrm{N}$ & $\mathrm{N}$ & $\mathrm{N}$ & $\mathrm{N}$ & $\mathrm{N}$ & $\mathrm{N}$ \\
\hline \multirow{3}{*}{ PG76 + GTR + SIS5\% } & $0 \%$ & & & & - & $\mathrm{N}$ & $\mathrm{N}$ & $\mathrm{N}$ & $\mathrm{N}$ & $\mathrm{N}$ \\
\hline & $5 \%$ & & & & & - & $\mathrm{N}$ & $\mathrm{N}$ & $\mathrm{N}$ & $\mathrm{N}$ \\
\hline & $10 \%$ & & & & & & - & $\mathrm{N}$ & $\mathrm{N}$ & $\mathrm{N}$ \\
\hline \multirow{3}{*}{ PG76 + GTR + SIS5 $\%+$ PE3\% } & $0 \%$ & & & & & & & - & $\mathrm{N}$ & $\mathrm{N}$ \\
\hline & $5 \%$ & & & & & & & & - & $\mathrm{N}$ \\
\hline & $10 \%$ & & & & & & & & & - \\
\hline \multicolumn{11}{|l|}{ \%rec } \\
\hline \multirow{3}{*}{ PG76 + GTR } & $0 \%$ & - & $\mathrm{S}$ & $S$ & $S$ & $S$ & $S$ & $S$ & $S$ & S \\
\hline & $5 \%$ & & - & $S$ & $S$ & $S$ & $S$ & $S$ & $S$ & S \\
\hline & $10 \%$ & & & - & $S$ & $S$ & $S$ & $S$ & $S$ & $S$ \\
\hline \multirow{3}{*}{ PG76 + GTR + SIS5\% } & $0 \%$ & & & & - & S & $S$ & $S$ & $S$ & $S$ \\
\hline & $5 \%$ & & & & & - & $S$ & $S$ & $\mathrm{~N}$ & $\mathrm{~S}$ \\
\hline & $10 \%$ & & & & & & - & $S$ & $\mathrm{~S}$ & $\mathrm{~N}$ \\
\hline \multirow{3}{*}{ PG76 + GTR + SIS5 $\%+$ PE3\% } & $0 \%$ & & & & & & & - & $S$ & $S$ \\
\hline & $5 \%$ & & & & & & & & - & S \\
\hline & $10 \%$ & & & & & & & & & - \\
\hline
\end{tabular}

N: nonsignificant; S: significant.

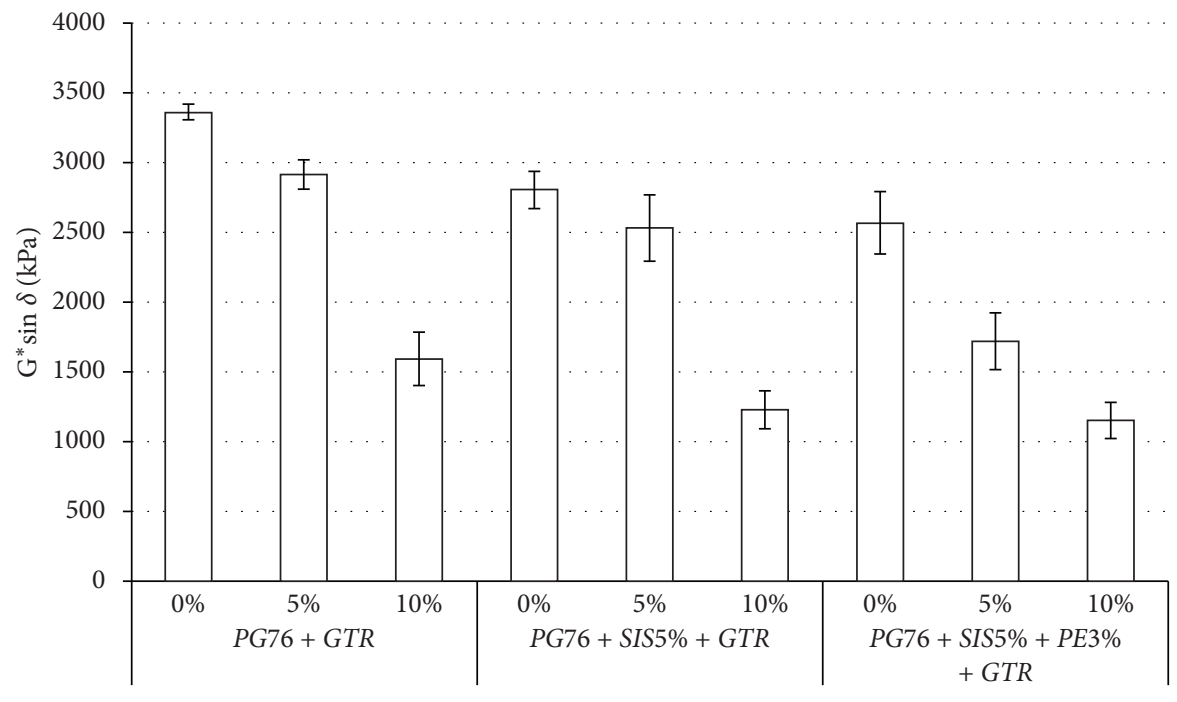

GTR content in PMA binder

Figure 7: G* $\sin \delta$ of the PMA binders with SIS, PE, and GTR at $25^{\circ} \mathrm{C}$.

minimum $m$ value of 0.300 are required by Superpave binder specifications. The decrease in stiffness leads to smaller tensile stresses in the asphalt binder and less chance for low-temperature cracking. The BBR test was performed at $-12^{\circ} \mathrm{C}$ to observe the effect of addition of SIS, PE, and GTR content on the low-temperature cracking properties of the PMA binders. Figures 8 and 9 illustrate the creep stiffness and $m$ values of the PMA binders with GTR, respectively. It is observed that the addition of GTR to the PMA binders resulted in lower values of creep stiffness, regardless of the base PMA binder types. Furthermore, the sequential addition of SIS and PE showed a decrease in stiffness values depending on each additive. The PG76+SIS5\% with GTR showed relatively lower stiffness values compared to the corresponding binders without SIS. The effect of PE which improved fatigue cracking property is not much evident in the result of stiffness value, but all values are lower than some PMA binders without $\mathrm{PE}$. This suggests that the addition of $\mathrm{PE}$ improves cracking performance. In addition, the $m$ values 
TABLE 6: Statistical analysis results of the $\mathrm{G}^{*} \sin \delta$ as a function of addition of SIS, PE, and GTR content $(\alpha=0.05)$.

\begin{tabular}{|c|c|c|c|c|c|c|c|c|c|c|}
\hline \multirow[t]{2}{*}{$\mathrm{G}^{*} \sin \delta$ at $25^{\circ} \mathrm{C}(\mathrm{RTFO}+\mathrm{PAV})$} & & \multicolumn{3}{|c|}{ PG76 + GTR } & \multicolumn{3}{|c|}{ PG76 + SIS5\% + GTR } & \multicolumn{3}{|c|}{$\begin{array}{c}\text { PG76 + SIS5 } \%+\text { PE3 } \%+ \\
\text { GTR }\end{array}$} \\
\hline & & $0 \%$ & $5 \%$ & $10 \%$ & $0 \%$ & $5 \%$ & $10 \%$ & $0 \%$ & $5 \%$ & $10 \%$ \\
\hline \multirow{3}{*}{ PG76 + GTR } & $0 \%$ & - & $\mathrm{S}$ & S & $S$ & S & S & S & S & S \\
\hline & $5 \%$ & & - & $S$ & $\mathrm{~N}$ & S & S & S & S & S \\
\hline & $10 \%$ & & & - & S & $S$ & S & S & $\mathrm{N}$ & S \\
\hline \multirow{3}{*}{ PG76 + GTR + SIS5\% } & $0 \%$ & & & & - & $\mathrm{N}$ & $S$ & $\mathrm{~N}$ & S & $\mathrm{S}$ \\
\hline & $5 \%$ & & & & & - & $S$ & $\mathrm{~N}$ & S & $\mathrm{S}$ \\
\hline & $10 \%$ & & & & & & - & S & $\mathrm{S}$ & $\mathrm{N}$ \\
\hline \multirow{3}{*}{ PG76 + GTR + SIS5\%+PE3\% } & $0 \%$ & & & & & & & - & $S$ & $S$ \\
\hline & $5 \%$ & & & & & & & & - & S \\
\hline & $10 \%$ & & & & & & & & & - \\
\hline
\end{tabular}

N: nonsignificant; S: significant.

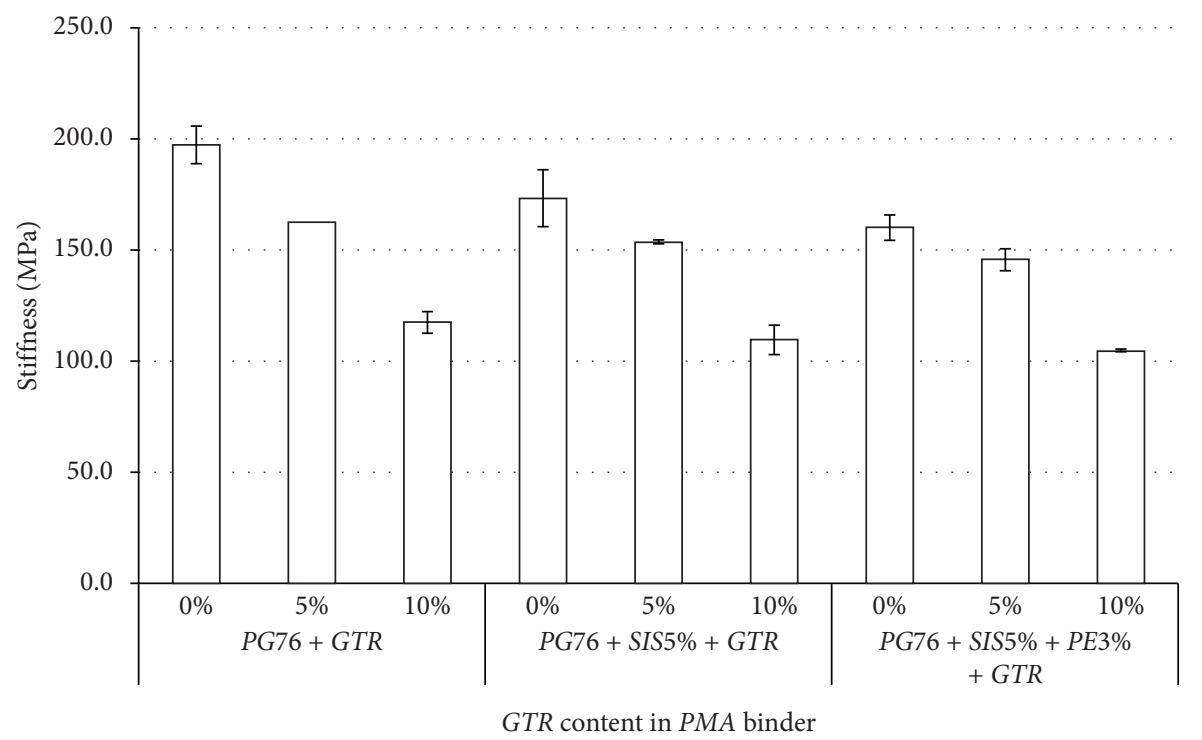

Figure 8: Stiffness of the PMA binders with SIS, PE, and GTR at $-12^{\circ} \mathrm{C}$.

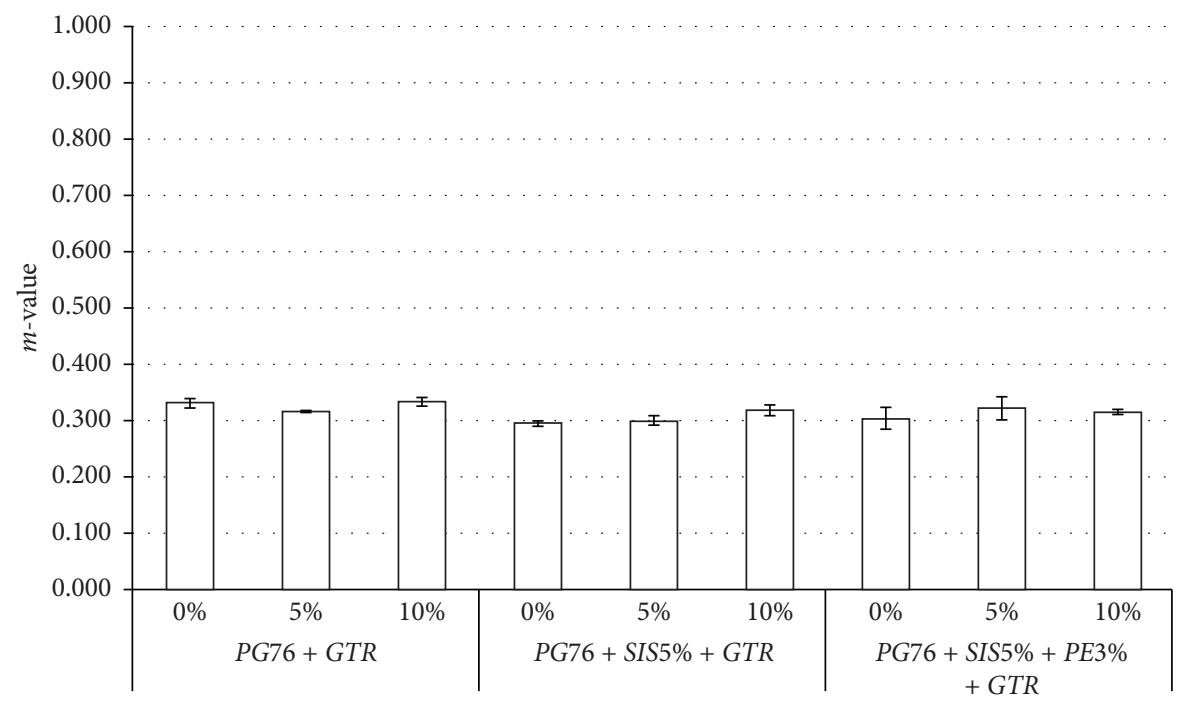

GTR content in PMA binder

FIgURE 9: $m$ value of the PMA binders with SIS, PE, and GTR at $-12^{\circ} \mathrm{C}$. 
TABLE 7: Statistical analysis results of the stiffness as a function of addition of SIS, PE, and GTR content $(\alpha=0.05)$.

\begin{tabular}{|c|c|c|c|c|c|c|c|c|c|c|}
\hline \multirow[t]{2}{*}{ Stiffness } & & \multicolumn{3}{|c|}{ PG76 + GTR } & \multicolumn{3}{|c|}{ PG76 + SIS5\% + GTR } & \multicolumn{3}{|c|}{$\begin{array}{c}\text { PG76 + SIS5 } \%+\text { PE3 } \%+ \\
\text { GTR }\end{array}$} \\
\hline & & $0 \%$ & $5 \%$ & $10 \%$ & $0 \%$ & $5 \%$ & $10 \%$ & $0 \%$ & $5 \%$ & $10 \%$ \\
\hline \multirow{3}{*}{ PG76 + GTR } & $0 \%$ & - & $\mathrm{S}$ & S & $\mathrm{S}$ & $\mathrm{S}$ & S & $\mathrm{S}$ & $\mathrm{S}$ & $S$ \\
\hline & $5 \%$ & & - & S & $\mathrm{N}$ & $\mathrm{N}$ & S & $\mathrm{N}$ & S & S \\
\hline & $10 \%$ & & & - & $\mathrm{S}$ & $\mathrm{S}$ & $\mathrm{N}$ & $\mathrm{S}$ & $\mathrm{S}$ & $\mathrm{N}$ \\
\hline \multirow{3}{*}{ PG76 + GTR + SIS5\% } & $0 \%$ & & & & - & $\mathrm{S}$ & S & $\mathrm{N}$ & $\mathrm{S}$ & S \\
\hline & $5 \%$ & & & & & - & S & $\mathrm{N}$ & $\mathrm{N}$ & S \\
\hline & $10 \%$ & & & & & & - & S & S & $\mathrm{N}$ \\
\hline \multirow{3}{*}{ PG76 + GTR + SIS5 $\%+$ PE3 $\%$} & $0 \%$ & & & & & & & - & $\mathrm{S}$ & S \\
\hline & $5 \%$ & & & & & & & & - & S \\
\hline & $10 \%$ & & & & & & & & & - \\
\hline
\end{tabular}

N: nonsignificant; S: significant.

TABLE 8: Statistical analysis results of the $m$ value as a function of addition of SIS, PE, and GTR content $(\alpha=0.05)$.

\begin{tabular}{|c|c|c|c|c|c|c|c|c|c|c|}
\hline \multirow[t]{2}{*}{$m$ value } & & \multicolumn{3}{|c|}{ PG76 + GTR } & \multicolumn{3}{|c|}{ PG76 + SIS5\% + GTR } & \multicolumn{3}{|c|}{$\begin{array}{c}\text { PG76 + SIS5 } \%+\text { PE3 } \%+ \\
\text { GTR }\end{array}$} \\
\hline & & $0 \%$ & $5 \%$ & $10 \%$ & $0 \%$ & $5 \%$ & $10 \%$ & $0 \%$ & $5 \%$ & $10 \%$ \\
\hline \multirow{3}{*}{ PG76 + GTR } & $0 \%$ & - & $\mathrm{N}$ & $\mathrm{N}$ & $\mathrm{S}$ & $S$ & $\mathrm{~N}$ & $\mathrm{~S}$ & $\mathrm{~N}$ & $\mathrm{~N}$ \\
\hline & $5 \%$ & & - & $\mathrm{N}$ & $\mathrm{N}$ & $\mathrm{N}$ & $\mathrm{N}$ & $\mathrm{N}$ & $\mathrm{N}$ & $\mathrm{N}$ \\
\hline & $10 \%$ & & & - & $\mathrm{S}$ & $\mathrm{S}$ & $\mathrm{N}$ & $\mathrm{S}$ & $\mathrm{N}$ & $\mathrm{N}$ \\
\hline \multirow{3}{*}{ PG76 + GTR + SIS5\% } & $0 \%$ & & & & - & $\mathrm{N}$ & $\mathrm{N}$ & $\mathrm{N}$ & $\mathrm{S}$ & $\mathrm{N}$ \\
\hline & $5 \%$ & & & & & - & $\mathrm{N}$ & $\mathrm{N}$ & $\mathrm{N}$ & $\mathrm{N}$ \\
\hline & $10 \%$ & & & & & & - & $\mathrm{N}$ & $\mathrm{N}$ & $\mathrm{N}$ \\
\hline \multirow{3}{*}{ PG76 + GTR + SIS5 $\%+$ PE3 $\%$} & $0 \%$ & & & & & & & - & $\mathrm{N}$ & $\mathrm{N}$ \\
\hline & $5 \%$ & & & & & & & & - & $\mathrm{N}$ \\
\hline & $10 \%$ & & & & & & & & & - \\
\hline
\end{tabular}

N: nonsignificant; S: significant.

did not seem to change much depending on the additives, although all values are higher than minimum 0.3 suggested by Superpave.

Using one-way analysis of variance, the statistical significance of the difference in the stiffness and $m$ value was examined (as shown in Tables 7 and 8). For all base PMA binders, the GTR content were found to have significant difference in terms of stiffness, whereas the changes in stiffness between each $10 \%$ GTR content of all PMA binders were statistically insignificant. This result indicates that the effect of SIS and PE is not effective to reduce the stiffness values of PMA binders with 10\% GTR. With respect to the $m$ value, it was evident that the changes in stiffness by different base PMA types and GTR contents were statistically insignificant.

\section{Summary and Conclusions}

To evaluate the performance properties of SBS PMA binders containing SIS, PE, and GTR, three different GTR percentage contents $(0,5$, and 10\%) were added into PG76 SBS PMA + 5\% SIS and PG76 SBS PMA + 5\% SIS + 3\% PE. All sample binders were produced with wet process and artificially short-term and long-term aged using the RTFO and the PAV procedures. A series of Superpave binder tests were carried out using the RV, the DSR, and the BBR to determine the physical and rheological properties (viscosity, rutting, fatigue cracking, and low-temperature cracking) of the binders. Also, MSCR test was conducted to deeply investigate the rutting properties. Based on the results, the following conclusions were made for the materials used in this study.

(1) Both the GTR and SIS modifiers increased the viscosity of the PMA binder, whereas the addition of PE significantly reduced the viscosity, indicating that the production and paving temperature of the PMA mixes can be decreased using the PE.

(2) In general, SBS PMA binders modified with SIS and GTR were found to be effective in increasing rutting resistance compared to the control SBS PMA binder. It is important to note that the addition of $\mathrm{PE}$ which caused lower viscosity seemed to have similar level of rutting resistance.

(3) According to the MSCR test results, the addition of SIS modifier significantly decreases the $\mathrm{J}_{\mathrm{nr}}$ value. In the case of \%rec, although it showed a tendency to decrease due to the addition of PE, the addition of $10 \%$ of rubber could offset the decreasing effect to have similar level of rutting resistance related to the elastic property. 
(4) From the DSR test at intermediate temperature, it is exhibited that the GTR content and SIS are considered to have positive effects on fatigue cracking resistance, and the addition of $\mathrm{PE}$ was useful to improve this effect.

(5) From the BBR at $-12^{\circ} \mathrm{C}$, stiffness values were decreased by SIS and GTR content. This result indicates that both additives positively influence the lowtemperature cracking resistance, as expected. In general, the addition of PE into the PMA binder with SIS and GTR content is observed to improve the stiffness at low temperature.

(6) It is recommended that the incorporation of PE can be considered in order to modify the SBS PMA binders with SIS and GTR to achieve better cracking resistance and more temperature reduction for mixing and compaction without negative effect on rutting resistance.

\section{Data Availability}

The data used to support the findings of this study are included within the article.

\section{Conflicts of Interest}

The authors declare no conflicts of interest regarding the publication of this paper.

\section{Acknowledgments}

This research was supported by the research grant from KICT through the Korea Agency for Infrastructure Technology Advancement funded by the Ministry of Land, Infrastructure and Transport of the Korean government (project no. 18TBIP-C125410-02).

\section{References}

[1] M. Buncher and C. Rosenberger, "Understanding the true economics of using polymer modified asphalt through life cycle cost analysis," Asphalt, vol. 12, no. 2, pp. 28-30, 2005.

[2] Y. Becker, M. P. Mendez, and Y. Rodriguez, "Polymer modified asphalt," Vision Tecnologica, vol. 9, p. 1, 2001.

[3] A. Adedeji, T. Grünfelder, F. S. Bates, C. W. Macosko, M. Stroup-Gardiner, and D. E. Newcomb, "Asphalt modified by SBS triblock copolymer: structures and properties," Polymer Engineering \& Science, vol. 36, no. 12, pp. 1707-1723, 1996.

[4] R. Roque, B. Birgisson, C. Drakos, and G. Sholar, "Guidelines for use of modified binders," Transportation Research Board, Gainesville, FL, USA, UF Project No. 4910-4504-964-12, 2005.

[5] U.S. Tire Manufacturers Association, 2017 U.S. Scrap Tire Management Summary, U.S. Tire Manufacturers Association, Washington, DC, USA, 2018.

[6] H. H. Kim, M. Mazumder, M.-S. Lee, and S.-J. Lee, "Effect of blending time on viscosity of rubberized binders with wax additives," International Journal of Pavement Research and Technology, vol. 11, no. 6, pp. 655-665, 2018.

[7] S.-C. Huang and A. T. Pauli, "Particle size effect of crumb rubber on rheology and morphology of asphalt binders with long-term aging," Road Materials and Pavement Design, vol. 9, no. 1, pp. 73-95, 2008.

[8] M. F. Azizian, P. O. Nelson, P. Thayumanavan, and K. J. Williamson, "Environmental impact of highway construction and repair materials on surface and ground waters," Waste Management, vol. 23, no. 8, pp. 719-728, 2003.

[9] B. Huang, L. Mohammad, P. Graves, and C. Abadie, "Louisiana experience with crumb rubber-modified hot-mix asphalt pavement," Transportation Research Record: Journal of the Transportation Research Board, vol. 1789, no. 1, pp. 1-13, 2002.

[10] H. H. Kim and S.-J. Lee, "Effect of crumb rubber on viscosity of rubberized asphalt binders containing wax additives," Construction and Building Materials, vol. 95, pp. 65-73, 2015.

[11] H. H. Kim, M. Mazumder, and S.-J. Lee, "Recycling of aged asphalt binders with wax warm additives," Road Materials and Pavement Design, vol. 19, no. 5, pp. 1203-1215, 2018.

[12] S. J. Lee, Characterization of Recycled Aged CRM Binders, Clemson University, Clemson, SC, USA, 2007.

[13] S. K. Palit, K. S. Reddy, and B. B. Pandey, "Laboratory evaluation of crumb rubber modified asphalt mixes," Journal of Materials in Civil Engineering, vol. 16, no. 1, pp. 45-53, 2004.

[14] B. E. Ruth and R. Roque, "Crumb rubber modifier (CRM) in asphalt pavements," in Proceedings ofthe Transportation Congress, vol. 1 and 2, Civil Engineers-Key to the World's Infrastructure, ASCE, Yokohama, Japan, 1995, Civil Engineers-Key to the World's Infrastructure.

[15] J. Shen and S. Amirkhanian, "The influence of crumb rubber modifier (CRM) microstructures on the high temperature properties of CRM binders," International Journal of Pavement Engineering, vol. 6, no. 4, pp. 265-271, 2005.

[16] G. B. Way, OGFC Meets CRM-Where the Rubber Meets the Rubber-12 Years of the Durable Success, The Asphalt Conference, Atlanta, Georgia, 1998.

[17] F. Xiao, P. E. Wenbin Zhao, and S. N. Amirkhanian, "Fatigue behavior of rubberized asphalt concrete mixtures containing warm asphalt additives," Construction and Building Materials, vol. 23, no. 10, pp. 3144-3151, 2009.

[18] L. Xiang, J. Cheng, and G. Que, "Microstructure and performance of crumb rubber modified asphalt," Construction and Building Materials, vol. 23, no. 12, pp. 3586-3590, 2009.

[19] P. Lin, W. Huang, N. Tang, and F. Xiao, "Performance characteristics of terminal blend rubberized asphalt with SBS and polyphosphoric acid," Construction and Building Materials, vol. 141, pp. 171-182, 2017.

[20] M. Mazumder, Characterization of crack sealant materials and implementation techniques, Ph.D. thesis, Texas State University, San Marcos, TX, USA, 2019.

[21] F. Zhang, C. Hu, and Y. Zhang, "The research for SIS compound modified asphalt," Materials Chemistry and Physics, vol. 205, pp. 44-54, 2018.

[22] H. U. Bahia, Critical Evaluation of Asphalt Modification Using Strategic Highway Research Program Concepts, Transportation Research Record, no. 1488, Washington, DC, USA, 1995.

[23] X. Nie, T. Hou, H. Yao, Z. Li, X. Zhou, and C. Li, "Effect of C9 petroleum resins on improvement in compatibility and properties of SBS-modified asphalt," Petroleum Science and Technology, vol. 37, no. 14, pp. 1704-1712, 2019.

[24] H. Wang, P. Apostolidis, J. Zhu, X. Liu, A. Skarpas, and S. Erkens, "The role of thermodynamics and kinetics in rubber-bitumen systems: a theoretical overview," International Journal of Pavement Engineering, vol. 21, no. 8, pp. 1-16, 2020. 
[25] H. Wang, X. Liu, H. Zhang, P. Apostolidis, T. Scarpas, and S. Erkens, "Asphalt-rubber interaction and performance evaluation of rubberised asphalt binders containing non-foaming warm-mix additives," Road Materials and Pavement Design, vol. 21, no. 6, pp. 1612-1633, 2020.

[26] R. L. Ott and M. T. Longnecker, An Introduction to Statistical Methods and Data Analysis, Cengage Learning, Boston, MA, USA, 2008.

[27] H. H. Kim, M.-S. Lee, and S.-J. Lee, "Performance evaluation of polymer modified asphalt (PMA) binders containing ground tire rubber (GTR)," International Journal of Pavement Research and Technology, vol. 12, no. 2, pp. 215-222, 2019. 